\title{
AMERICAN LINGUISTICS \\ AND THE TEACHING OF ENGLISH
}

\author{
CHARLES C. FRIES \\ University of Michigan
}

(The following article originally appeared in Revue des Langues Vivantes, XXI (1955). Summarizing points made in Professor Fries' talks to teachers of English during his recent trip to Germany, it reviews certain aspects of structural linguistics as recently developed in the United States that have special significance for the teaching of English as a foreign language. ${ }^{1}$ We are grateful for the opportunity of presenting it here.)

\section{A merican Structural Linguistics}

1. In general the scientific study of language as practiced in the United States throughout the 19th century was based upon and did not depart greatly from that of the long line of European scholars in historical-comparative linguistics, in phonetics, and in linguistic geography. In contrast with these linguistic activities, however, much of what we now call our "Structural Linguistics," 2 with its beginnings just after the first World War seems to have had a somewhat independent development and differs in some respects from the structuralism of the Cercle linguistique de Prague and from that later developed in the Cercle linguistique de Copenhagen.

\footnotetext{
${ }^{1}$ The same principles have equal significance for the teaching of other foreign languages.

${ }^{2}$ Some still speak of "Descriptive Linguistics" as opposed to "Historical Linguistics" and equate "Structural Linguistics" with "Descriptive Linguistics." It is true that our "Structural Linguistics" arose in connection with the descriptive analysis of living languages, but its principles and new insights have significance for the complete range of linguistic data and are now providing a basis for very fruitful restudy of much of our historical evidence. (See the work on the Phonemes of Gothic, on the development of the phonemic system of English through Middle English, on the rise of new consonant clusters in English, on the development of a new system of structural signals in English.)
} 


\section{LANGUAGE LEARNING}

Certain beginnings of the views that characterize our Structural Linguistics appear in statements from Edward Sapir, in his book Language, published in 1921. They are statements concerning his experience when he was trying to record, analyze, and describe some of the American Indian languages. ${ }^{3}$ Structural linguistics in the United States differs markedly from the somewhat parallel developments in Europe because it arose out of and has always been closely connected with the effort to analyze and describe completely the many diverse and complex American Indian languages still spoken in the United States and neighboring countries - languages whose structures differ remarkably from those of the languages of the Indo-European and other well-known language families. 4 The technical terminology now used in American Structural linguistics came slowly into use after the publication of Bloomfield's book in 1933. The word phoneme is but one of these technical words that follow a pattern-morpheme, taxeme, sememe, tagmeme, kineme, grameme, behavioreme, uttereme,-and derives its meaning, for us not from its former European use, but from our particular experience in the

${ }^{3}$ Edward Sapir, Language (1921) p. 58, p. 57.

"I found that it was difficult or impossible to teach an Indian to make phonetic distinctions that did not correspond to 'points on the pattern of his language; however these differences might strike our objective ear, but that subtle, barely audible, phonetic differences, if only they hit the 'points in the pattern' were easily and voluntarily expressed in writing."

"Two historically related languages or dialects may not have a sound in common, but their ideal sound system may be identical patterns."

${ }^{4}$ Very few people outside the United States, and practically no one within the United States, except a few hundred linguists and anthropologists, have any realization of the great number and tremendous diversity of American Indian languages. We know now, for example, that there are, in the United States alone, at least fifty-four different families of languages parallel with such families as the Indo-European, the FinnoUgric, the Semitic-Hamitic, the Sino-Thibetan. In Mexico there are twenty additional families. Just as the Indo-European family has its large number of separate and distinct languages (Russian, German, French, English, Greek, Persian, etc.) so some of these families of A merican Indian languages have as many as 20 to 30 different languages. 
structural analysis of languages. Many of those who have contributed most to the development of American structural linguistics have been either linguistic-anthropologists as was Sapir or have been linguists as was Bloomfield who spent much time among the Indians studying their languages. Perhaps the one particular publication which could be said to mark especially the beginning of the recent structuralism in the United States is Edward Sapir's "Sound Patterns in Language," which appeared in Language, the quarterly journal of the Linguistic Society, in its first volume, in 1925.

2. This "structuralism" of American linguistics has resulted in a changed view of the nature of human language -a changed view of what constitutes the basic functioning units of a language. Consequently it has led to a new understanding of the precise problems involved in learning and in teaching a foreign language. Two important facts that came out of Sapir's early experience [See note no. 3 above] form part of the very foundation of this new view of language.

(a) The same phonetic differences may have (and probably will have) entirely different structural values from language to language.

(b) There is power or force in the structural system itself. (The habits that constitute the control of one's native language are not habits concerning items as items, but habits concerning an ordered system of structural patterns.)

The following examples may help to clarify these two statements. In English we have the sound of " $k$ " at the beginnings of each of the following words kill, coal, call. But these three " $k$ " sounds are phonetically quite different, i.e. the position at which the top of the tongue touches the roof of the mouth as it stops and then releases the flow of air through the mouth is much farther forward in pronouncing kill than it is in pronouncing coal. In pronouncing call it is still farther

\footnotetext{
${ }^{5}$ Modern physcis and chemistry have revealed certain facts concerning the nature of matter which seem to me to offer something of an illustration that may help to understand the significance of these two statements. For example, molecule A may have exactly the same atoms and the same number of atoms as molecule $B$, but if in molecule $A$ the arrangement (the structural connections) of these atoms differs from that of the arrangement in molecule $B$, then the two molecules will have entirely different properties.
} 


\section{LANGUAGE LEARNING}

back. In English this phonetic difference in the three " $k$ " sounds is mechanically bound with the particular vowel that follows the " $\mathrm{k}$ ", and is a phonetic difference that is never used to separate words. English speakers find it very difficult to make and even to hear these differences in the " $k$ " sound without attaching it to the different vowels. On the other hand in a number of Dravidian languages these differences of position in making " $k$ " sounds are not attached to particular vowels, and are used to distinguish different words. The same phonetic differences of the three positions of forming these " $\mathrm{k}$ " sounds have entirely different structural values in English and in Tamil. More than that, the power or force of the structural arrangement of these phonetic differences of " $\mathrm{k}$ " in English is so strong that it is exceedingly hard for a native speaker of English, as an adult, to learn not only to make these differences for " $k$ " without connection with their particular vowels but even to hear these differences in the stream of speech.

On the other hand, we in English separate many words solely by means of the phonetic difference of "voicing" a consonant, e.g. s/z, or $\mathrm{k} / \mathrm{g}$; race - raise; rice - rise; mace maize; tack - tag; back - bag; rack - rag. Spanish speakers, trying to learn English, at first find it very difficult to hear and distinguish, in the stream of speech, the words separated solely by the phonetic difference between [ $s$ ] and [z] and German speakers those separated solely by the phonetic difference between $[\mathrm{k}]$ and $[\mathrm{g}]$, because for these languages these phonetic differences are not "points on their pattern" as they are for English.

From the point of view of our structural linguistics, the phonetic difference between [ $\mathrm{s}]$ and [ $\mathrm{z}$ ] is only phonetic in Spanish, but in English this phonetic difference is also phonemic(structurally significant). In similar fashion the phonetic difference between the kinds of " $k$ " indicated above are only phonetic in English but are phonemic in Tamil. Phonetic differences are always phonetic differences in any and every language. When phonetic differences are structurally significant in a particular language (e.g. used in the language to mark or distinguish one meaning unit from another) then they are phonemic for that language. 


\section{THE TEACHING OF ENGLISH}

The differentiation of those items of a language that have structural significance from those that have not is not limited to a consideration of the sound system only, but runs through an analysis of all the other levels of linguistic phenomena. In other words, we have generalized the views that first grew up in connection with our dealing with language sounds and applied the principles to our analysis of intonation, of grammar, of context, and even of non-linguistic behavior. ${ }^{6}$ This extending of the same principles to other linguistic matters shows itself in the creation of two new words by cutting off the portions of the words phonetic and phonemic that have to do with "sounds," leaving simply etic and emic. Every aspect of human behavior can thus be approached from an etic point of view, i.e. considering the items as items, or from an emic point of view, structurally, i.e. seeking the functioning patterns in a particular society.

3. This structural approach to language does not ignore meaning of any kind. It attempts to sort out the various kinds or levels of meanings and to discover how, in any particular language, each kind or level is communicated from one individual to another.?

\footnotetext{
${ }^{6}$ See the new book by Prof. Kenneth L. Pike, Language in Relation to a Unified Theory of the Structure of Human Behavior. (The first part of a preliminary edition of this book has just been published.) Some of us have also been giving considerable attention to the application of the principles of this new approach to various matters of literary criticism and to the historical study of language and culture.

${ }^{7}$ The following quotations from $\mathrm{L}$. Bloomfield are pertinent.

"To put it briefly, in human speech, different sounds have different meanings. To study this coordination of certain sounds with certain meanings is to study language." Language, (1933), p. 27.

"Until our knowledge of acoustics has progressed far beyond its present state, only the latter kind of record [a record in terms of phonemes] can be used for any study that takes into consideration the meaning of what is spoken," Language, (1933), p. 85.

"Only in this way will a proper analysis (that is, one which takes account of the meanings) lead to the ultimate constituent morphemes." Langrage. (1933), p. 161 .

See also C.C. Fries, "Meaning and Linguistic Analysis," in Language. $\mathrm{XXX}, 1954$, pp. 57-68.
} 


\section{LANGUAGE LEARNING}

In our discussions here, since we shall be especially concerned with our structural linguistics in connection with the practical matters of language teaching, it will be necessary to limit our consideration of the problems of meaning and to put emphasis upon those matters that have especial significance for the stages of language learning covered by the schools. Here then we are primarily concerned with language in its social role of making possible the sharing of experience, of procuring cooperation between the members of a group. It is language as sets of signals which, consciously given by one individual, produce predictable responses of recognition or action in another individual or individuals. 8 Three layers or kinds of meaning signals are of especial importance for our purpose here.

(A) The signals by which one lexical item is distinguished from another. 9

Phonemes are one set of functioning markers by which differing lexical items are recognized.

(1) The top of this pen was bent over

(2) The top of this pin was bent over

(3) The top of this pan was bent over

(4) The top of this pan was sent over

The differences of meaning of sentences (1), (2), (3), above depend on the different lexical items pen, pin, and pan, in each. Here the different lexical items are identified by the contrast of the single functioning markers, [ $\epsilon$ ] [i] [ae].

${ }^{8}$ I would define a language then as follows (See C.C. Fries, "Meaning and Linguistic Analysis", in Language, XXX, 1954, p. 64):

"A language is a system of recurring sequences or patterns of 'sames' of vocal sounds [or, of course, representation of them in writing] which correlate with recurring 'sames' of stimulus-situation features, and which elicit recurring 'sames' of response features."

The language function is fulfilled only in so far as it is possible to predict the response features that will regularly be elicited by the patterns of linguistic forms.

9 The establishing of the meanings of the words themselves, as, for example, the work of the great Oxford Dictionary and the period dictionaries that are following it, and the describing of the lexical sets by which the precise meaning is selected out of many had to be given very brief treatment because of the limitations of time. 


\section{THE TEACHING OF ENGLISH}

The difference of meaning of sentence (3) and sentence (4) depends on the difference of the lexical items bent in (3) and sent in (4). These lexical items are separated by the contrast of the single functioning marking units [b] and [s].

(B) The signals by which certain structural meanings are distinguished.

Sometimes the signals of structural meanings are intonation (contrastive pitch sequences), sometimes contrastive order or position, sometimes contrastive word forms, sometimes function words. ${ }^{20}$

The difference of structural meaning in the following pair of sentences-that sentence (a) is a statement, and sentence (b) a question-is signalled by the contrast of position or order. ${ }^{11}$

(a) Mr. Smith is a young man

(b) Is Mr. Smith a young man

The difference of structural meaning in the following pair of sentences-that sentence (a) is a statement, and sentence (b) is a question-is signalled by the function-word do.

(a) The students swim here every Tuesday

(b) Do the students swim here every Tuesday

In sentence (a) of the following pair, the clause which is there is a "modifier" of the word class; in sentence (b) the clause which are there "modifies" the word books. The position of these clauses is the same in both expressions. The difference in structural significance is signalled by the difference in the forms is and are.

(a) The books for the class which is there are ready for distribution

(b) The books for the class which are there are ready for distribution

The difference between the meaning of the following phrases is signalled by the ending-ing in (a) as contrasted with the ending ed in (b).

${ }^{\circledR 10}$ See C.C. Fries, The Structure of English, 1952.

${ }^{11}$ The contrasts here given can depend solely on position or order. The significant intonation curve can be the same in both sentences. See Fries, The Structure of English p. 143, and note no. 4 p. 147. 


\section{LANGUAGE LEARNING}

(a) a water softening solution

(b) a water soften $e d$ solution

In both phrases the word solution is the "head" and the other words are "modifiers." But in the first phrase, with the -ing ending on the word soften, the meaning is that the solution acts upon the water, in the second phrase, with the -ed ending on the word soften the meaning is that the water acts upon the solution.

The difference in the intonation pattern in the following phrases signals the difference in meaning ${ }^{12}$

(a) a mo ving van (ein Mbbelwagen)

(b) a moving

In similar fashion the white house is quitedifferent in meaning from the white house and a dancing girl is different in meaning from a dan cing girl.

(C) The signals by which various kinds of social-cultural meanings are communicated.

The linguistic meanings of our utterances-the lexical meanings and the structural meanings, to which we give great attention-constitute only part of the total meaning of these

12 In this marking of "emic" intonation (i.e. pitch sequences that signal certain structural meanings) four contrastive levels serve to indicate all the essential patterns. These are relative pitch levels, not absolute intervals.

$$
\begin{array}{ll}
1 & 2 \\
3 & a \\
4 & \text { mo ving van a }
\end{array}
$$

Number 3 represents the usual voice level.

Number 2 represents one step above the usual voice level. Number 4 represents one step below the usual voice level.

Number 1 (not used here) represents two steps above the usual voice level. 


\section{THE TEACHING OF ENGLISH}

utterances as they function practically in a society. In addition to the regularly recurring responses to the lexical items and to the structural arrangements, there are also throughout a linguistic community recurring responses to unique whole utterances or sequences of utterances. Rip Van Winkle's simple utterance "I am a poor quiet man, a native of the place, and a loyal subject of the King, God bless him!" almost caused a riot, not because of the linguistic meaning signalled by the lexical items and the structures, but because the unique utterance as a whole, now, after the American Revolution, meant to the group that he was a confessed enemy of the newly established government. Twenty years before, this statement would have caused no such reaction. It would have meant simply that he was a "good" citizen. The linguistic meaning was the same as it would have been twenty years earlier; only its "social" or "cultural" meaning had changed. The utterances of a language that function practically in a society therefore always have both linguistic meaning and social-cultural meaning.

4. This structural descriptive analysis of language as discussed here is not a matter of just different terminology for older phonetic and grammatical ideas or meanings. The new technical terms that are used have NO EQUIVALENTS in the older terminology. "Phoneme" is not just another word for so called "broad" or "gross" phonetic differences as against "narrow" and "fine" phonetic distinctions. A "phonemic" transcription operates on an entirely different basic principle than does a "broad phonetic" transcription. "Function words," as used in "The Structure of English," are not the same as "empty words" in contrast with "full words" as used by Henry Sweet and others. Many "function words" do have lexical meaning. ${ }^{13}$ The defining characteristics by which the words of authentic living utterances are recognized as belonging to Classes I, II, III or IV are not those of the usual definitions of the "parts of speech." Class III .cannot be equated with "adjective" nor Class IV with "adverb" as these older terms are" usually employed.

${ }^{13}$ See C. C. Fries, The Structure of English, pp. 104-109. 


\section{Linguistics and Language Teaching}

1. The new approach to language teaching which has been derived from this new approach to language analysis and description is not in any way limited to the mechanical aspects of language.

(A) This approach to language teaching does not in any way narrow our view of what has to be done in order to learn a language well. It assumes that the fundamental purpose or objective of language teaching is to achieve an understanding, as complete as possible, between people of different linguistic backgrounds. It furnishes a systematic method of finding out the functioning patterns of not only the sound segments of a language, but also of its rhythm and intonation, its grammatical system, its lexical sets (i.e., the functioning verbal contexts), as well as its whole range of social and cultural meanings.

(B) This approach to language teaching uses the "oral approach" primarily in the first stage of language learning and does not reject reading and writing in any stage of language learning. This "oral approach" is not the same thing as the "direct method," and must not be confused with the limitations of the "direct method." The name "oral approach" is primarily a name to describe the end to be attained in the first stage of language learning rather than a descriptive limitation of the permissible devices to attain that end. In the first stage of learning a new language, the end is that the basic structural patterns, with a limited vocabulary, are to be learned so well that they can be produced orally, automatically, and without hesitation, when the learner is confronted with the appropriate situation. To the accomplishment of this end, not only oral practice is used but also every other means of learning, including writing and reading. After the first stage of language learning in accord with this approach the teacher or the student may devote himself entirely to reading and writing. 15

\footnotetext{
${ }^{14}$ See C. C. Fries, Teaching and Learning English as a Foreign Language (1945), especially Chapter V, pp. 57-61.

${ }^{15}$ See C. C. Fries, Teaching and Learning English as a Foreign Language (1945), pp. 5-9.
} 
(C) This approach to language teaching is not just a new set of classroom procedures or devices for teaching-it is not primarily a new method as such. It is not confined to mechanical matters and limited to narrow utilitarian purposes. The fundamental feature of the "new approach" to language teaching is not a greater allotment of time, is not smaller classes, is not even a greater emphasis on oral practice. The fundamental feature of this new approach to language teaching is a new basis upon which to build the teaching materials. This new approach to the selection and ordering of the materials for teaching rests upon

(a) a scientific descriptive analysis of the language to be learned, e.g. , English;

(b) a similar scientific descriptive analysis of the language of the learner, e.g., German;

(c) a systematic comparison of these two descriptive analyses in order to bring out completely the differences of structural patterning of the two language systems.

But these descriptions and this systematic comparison of the native language of the student with that of the language to be learned is not the material to be taught. It constitutes rather the basic matter upon which to build satisfactory classroom exercises which will contain the significant contrasts that must be mastered as new molds or patterns for the new language material. We assume that our first step is to learn to use the new language rather than to acquire detailed information about that language. The structural analyses and the systematic comparison indicated above are matters not for the ordinary student but for the makers of the textbooks and for the training of the teachers. Good teachers of a foreign language have often, from their experience, hit upon many of the special difficulties of their students. But such good results from practical teaching experience alone are unsystematic and uneven because they are not related to any principle which would provide a thorough and consistent check of the complete language material itself and reveal the essential nature of the difficulties. Learning a foreign language is always a matter of acquiring a new set of language habits against a background of an older set of language habits. The problems of the Spanish speaker in learning English differ 


\section{LANGUAGE LEARNING}

from those of the Portuguese speaker; and those of the German speaker differ from those of both the Spanish and the Portuguese. The procedures of a sound structural analysis can provide for the teacher a whole range of new insights into the nature and content of the precise problems with which his pupils must struggle.

2. This new approach to the analysis of the linguistic material itself, based upon a new view of the nature of the functioning signals of a language, does furnish the basis also for some principles of method.

(A) Accuracy comes first, not the learning of an extensive vocabulary. The accuracy to be achieved here, is first, the mastery of the sound system--to hear and to produce the distinctive sound contrasts in the stream of speech. It is, second, the mastery of the features of arrangement (forms, intonation, position) that constitute the signals of structural meanings. These are the matters that the native speaker as a very young child has acquired as unconscious habits, so early that, like learning to walk, he cannot remember the learning process. These matters must become automatic habits for the learner of a new language. Of course they cannot be learned in a vacuum. There must be sufficient vocabulary to operate the structures and represent the sound system in actual use, but the learner is not ready to devote his chief attention to expanding his vocabulary until accuracy of the patterns of contrast of sound segments, of intonation, of forms, of position, within a limited range of expression, has become largely automatic habit.

(B) All apsects of the teaching must proceed by contrasts of items in structure not by isolated items as items. Practice with significant sound features for example, must always deal with these features in contrastive sequences, first in pairs or groups of words with minimum contrasts (bed - bad; luck - lock - look; insight - inside) ; then with such words in contrastive sentences (It was unly a little red-It was only a little raid); and finally with such contrasts in paragraphs representative of the stream of speech.

(C) The pattern practice to make automatic the control of the significant contrasts of the various sets of signals a lapguage uses must not be simply repetitive drill. Imitation and 
repetition is of course the first step. The next step involves productive conscious choice among several patterns-with the selection of the pattern as the point of attention. The third step aims at an automatic, spontaneous selection of a pattern with the attention centered not on the structural patterns themselves but on changing situations and shifted meanings, introduced by a variety of differing vocabulary items.

It is the practical use of the linguistic scientist's techniques of language analysis and description in the choice and sequence of materials and the principles of method that grow out of these materials that lies at the heart of the "new approach to language learning."

3. This new view of the nature of the functioning signals of a language provides the basis for a new approach to the building of tests and measures of progress and achievement in the mastery of a new language.

(A) With the descriptive analyses available of both the language to be learned and the language of the learner [see II, (C), (a), (b), (c), above ] it is possible in tests to avoid the great range of insignificant language items, and to center attention upon the comparatively few that can be proved to be of strategic importance. Thus, brief and easily administered tests can now be constructed which can measure the progress and achievement of both beginning and advanced students with a high degree of validity.

(B) In outward form, the tests based upon such scientific descriptive analyses may appear to confine themselves to the simple mechanical details and not to differ from the many so-called "objective" tests formerly published. The fundamental difference of the tests based upon this new approach to language cannot be detected by an inspection or examination of the content by. those who are not trained in scientific descriptive analysis and who are not familiar with the results of such analysis as applied to both the languages involved.

(C) Tests of this kina can be so constructed that the ordipary class-room teacher can administer them and can interpret their results in terms of norms or standards that have been established for each particular test. Such tests, however, can not be constructed by the ordinary teacher for himself. They cannot be constructed by one who is an expert in 


\section{LANGUAGE LEARNING}

test construction only. They must be the work of such an expert who has at hand the descriptive materials of the languages involved and is himself trained to understand their significance. 16

\section{Structural Linguistics and} The Culture of a People

1. If, as indicated above $[\mathrm{II}, 1,(\mathrm{~A})$,$] ; the fundamental$ purpose or objective of foreign language teaching is to achieve an understanding, as complete as possible, between people of different linguistic backgrounds, then to deal with the culture and life of a people is not just an adjunct of a practical language course, something alien and apart from its main purpose, to be added or not as time and convenience may allow, but an essential feature of every stage of language learning.

(A) To achieve this end, we of the English Language Institute ${ }^{17}$ have first of all agreed to accept a particular attitude and point of view that is not always the attitude and view of all groups in our communities. Four differing groups can be roughly identified in nearly all communities.

(a) There are those people who are ultra-nationalistic. They don't like "foreigners" or things "foreign." They feel that what they have in their own community is better than anything in another community that differs from theirs. Abroad, they constantly point out the differences between what they find and what they have at horne-always to the disparagement of things abroad. The ultra-nationalistic group find it very difficult to "understand" a foreign culture.

\footnotetext{
${ }^{16}$ See articles by Prof. Robert Lado in "Selected Articles from Language Learning" (1953), pp. 169-211.

"Linguistic Science and Language Tests," pp. 169-176.

"Survey of Tests in English as a Foreign Language," pp. 177-192.

"Testing Control of the Structure of a Foreign Language," pp. 193211.

${ }^{17}$ At the English Language Institute of the University of Michigan we have been struggling for more than 15 years with the problems involved in this approach to the understanding of the culture and life of various peoples.
} 
(b) There are those people who hold just the opposite view--the "sentimental tourists." They feel that anything that comes from abroad is better than what they have at home. As they travel they seek the very "strange" customs and dress, and collect picturesque and spectacular items. The "sentimental tourists" practically never even attempt to grasp the "patterns" of living in a foreign culture.

(c) There are those who are intellectually curious. They collect all sorts of information about a people and may know a great deal abort the history, the political system, the economics even the literature, the art, the music of that people. But for them, all this information remains as mere knowledge and is never built into real understanding of the people. We believe that understanding must rest on information but that information by itself is not understanding.

(d) There are those who struggle to achieve real understanding and sympathetic insight into the way a foreign people regard the various activities of their own life and ways. They try to build up a vivid imaginative realization of what the history, the social practices, the songs, the physical features of the land really mean to the foreign people themselves. It is this point of view that we have adopted in our approach to the culture of a people and have assumed that progress toward the achieving of this kind of sympathetic understanding is the ultimate measure of the success of each stage of language teaching.

(B) From this point of view the words, the linguistic forms of a language, never "mean" the words, the linguistic forms of another language, they "mean" the specific, concrete, experience of the native users of that language. Translation, therefore, on the very elementary level, which seeks word for word equivalents without attention to the very differing content of the specific experience and attitudes covered by these words and linguistic forms for the users of each of the two languages involved, very often leads away from the kind of sympathetic understanding which is our fundamental purpose in all language teaching.

2. The content of the cultural materials to be dealt with presents many problems. 


\section{LANGUAGE LEARNING}

(A) Most of the cultural materials usually discussed in relation to language teaching concern features of the "overt" or external culture of a people-the history (often rather strictly political history), the geography, the educational system, the religious groups, the social classes, the music, the art, the literature. ${ }^{18}$ The selection of the specific matters to be included in each of such topics is seldom based upon any consistent and fundamental principle. Seldom is it recognized that even in matters of this level the same acts of overt behavior will very probably have very different cultural or structural values in two different societies. ${ }^{19}$ The search, therefore, must always aim at discovering the structural patterns of the overt culture if one is to make any progress toward understanding the specific practices of a people. Here too, those who grow up in a different culture have a whole range of "blind spots" which only the processes of a sound structural technique of analysis can help to overcome. The following quotation from Edward Sapir ${ }^{20}$ states the matter precisely.

"It is impossible to say what an individual is doing unless we have tacitly accepted the essentially arbitrary modes of interpretation that social tradition is constantly suggesting to us from the very moment of our birth. Let anyone who doubts this try the experiment of making a painstaking report of the actions of a group of natives engaged in some activity, say religious, to which he has not the cultural key. If he is a skilful writer, he may succeed in giving a picturesque account of what he sees and hears or thinks he sees and hears, but the chances of his being able to give a relation of what happens, in terms that would be intelligible and acceptable to the natives themselves, are practically nil. He will be

\footnotetext{
18 In the past, the literature of belles-lettres was often the sole material included.

19 The situation on this lewel is quite similar to that for the different structural values of the physically same phonetic features of a language. (See above I, 2).

${ }^{20}$ Quoted from Selected Writings of Edward Sapir on Language, Culture, and Personality, ed. by D.G. Mandelbaum, pp. 546-547.
} 


\section{THE TEACHING OF ENGLISH}

guilty of all manner of distortion; his emphasis will be constantly askew. He will find interesting what the natives take for granted as a casual kind of behavior worthy of no particular comment, and he will utterly fail to observe the crucial turning points in the course of the action that give formal significance to the whole in the minds of those who do possess the key to its understanding."

(B) In finding and selecting the cultural materials of those matters that are not of the overt or external kind the problems increase in number and in difficulty. These are matters that are significant in that differing practices often cause friction but are taken for granted by the natives themselves to such an extent that they are not aware that they exist.

In some countries, for example, it is the practice to "shake hands" in connection with greetings and leave-takings even of the most informal kind. In other countries this "shaking hands" occurs only upon more formal occasions. Unconsciously, then, those who are accustomed to shake hands upon all such occasions will interpret the neglect of this social act by those for whom it is not the custom as unfriendliness or crudity.

In some national cultures the call for silence in a group when a speaker is about to begin uses the voiceless spirant " $s$ " sound. In the United States the use of this sound when a speaker is about to begin is a gross insult. For English speakers in the United States the call for silence uses the voiceless spirant "sh" sound, $\left[\int\right]$. Those who, in the call for silence, use the " $s$ " sound (which in the United States is called a "hiss") sometimes grossly insult an American speaker when they are really trying to help him.

Americans, Britons, and Germans, as they eat, each use their forks according to a different pattern. Sometimes Americans or Britons, or Germans will react to this behaviour pattern of the others as something crude or even offensive. Cutting potatoes with a knife as part of the process of eating has a social significance for some German groups that it does not have for many other linguistic groups of western European culture. 
Differing cultural patterns of this kind seem trivial as one gives a few examples but the actual number of such characteristic differences between two peoples is tremendous and they usually cause friction and hostility in proportion to the degree to which they are not recognized and not known.

The principles and techniques of the structural approach can here also help to avoid many of the worst pitfalls in the selection of the content of the cultural material that must become a fundamental part of any really satisfactory language course.

(C) The effective use in teaching, of even the best selected cultural materials presents exceedingly difficult problems. After the range of important cultural patterns has been established and the content of these materials defined it is no simple matter so to deal with them in the various stages of language learning that those of a differing cultural background can achieve a sympathetic insight into the new way of evaluating experience. In some way the life experience, the modes of behavior, the bundles of history, the evaluations of "proper" and "improper," of right and wrong, which have been the undifferentiated and unconscious background of all the "talk" of the people who have used the foreign language all their lives must be vividly realized imaginatively by learners who have had a very different life experience. In some way the learner of a foreign language must "start as a child and grow up again" in a different way of grasping experience. The problem lies in finding the way to achieve imaginatively what cannot be accomplished physically. We have hitherto expected to achieve such a basis of understanding through information, through literature, and through the cinema. But we now realize more clearly that such information is always evaluated through the patterns of culture of the learner; the literary experience created arises out of and is formed by the elements that have become the imaginative repertoire of the learner; the foreign movies are seen and reacted to not in terms of the people for whom they were made, but in terms of a people who cannot realize all that is taken for granted by the producers to give their production the dramatic surface necessary for grasping the portrayed life situations in satisfactory proportion. Boys in 


\section{THE TEACHING OF ENGLISH}

secondary schools in Germany cannot, by simply reading the adventure books written for secondary school boys in the United States, achieve any understanding of the imaginative experience these books build up for such boys in the States. All cultural materials of a foreign language must in some way be attached to or built into the particular cultural experience of the readers, if they are to serve the purposes of understanding.

We have thus been struggling to develop not only our techniques of analysis to establish and define the functioning patterns of behavior of a foreign people and to gather the materials through which these patterns are clearly realized, but also our techniques for making a systematic comparison of the functioning patterns of two cultures and to break through the barriers that prevent the sympathetic vivid imaginative realization of understanding.

\section{A SELECTED BIBLIOGRAPHY OF USEFUL MATERIALS}

(For those interested in some of the chief aspects of American linguistics and the practical application of linguistics to the problems of teaching English as a foreign language.)

Charles C. Fries

1. Teaching and Learning English as a Foreign Language. (University of Michigan Press, Ann Arbor, Michigan, 1949, 153 pp.)

2. The Teaching of English. (A series of essays on "What is Good English?" "Teaching the English Language." "Teaching Literature.")

(Reprinted by George Wahr Publishing Company, Ann Arbor, Michigan, 1949, $251 \mathrm{pp}$. First published in 1925 and in 1927).

3. English Word Lists. (A study of their adaptability for instruction.) (First published by American Council on Education, Washington, D.C., 1940, 109 pp.)

(Now available as reprinted by George Wahr Publishing Company, Ann Arbor, Michigan, 1950.)

4. American English Grammar. (The grammatical structure of Present-day American English with especial reference to social differences or class dialects.)

(D. Appleton-Century Company, New York, 1940, 313 pp., also as Monograph 10, National Council of Teachers of English.) 


\section{LANGUAGE LEARNING}

5. The Structure of English. (An introduction to the construction of English sentences.)

(Harcourt, Brace and Company, 1952, 304 pp.)

6. The Periphrastic Future with Shall and Will in Modern English" (in Publications of the Modern Language Association, XL, 1925, pp. 960-1040).

7. "The Expression of the Future" (in Language, III, 1927, pp. 87 $-95)$.

8. "The Rules of the Common School Grammars" (in Publications of the Modern Language Association, 42, 1927, pp. 221-237).

9. "The Inflected Genitive in Present-day English" (in Language, XIV, 1938, pp. 121-133).

10. "The Development of the Structural Use of Word-Order in Modern English" (in Language, XVI, 1940, pp. 199-208).

11. "Some Implications of Linguistic Science" (in English Journal, XXXII, 1943).

12. "Harle as a Function Word" (in Language Learning, 1948, pp. 4-8).

13. "The Chicago Investigation of Second Language Teaching" (in Language Learning, II, 1949, p. 3 and reprinted in Selected Articles from Language Learning, 1953, pp. 65-75).

14. Meaning and Linguistic Analysis" (in Language, XXX, 1954, pp. $57-68)$.

Charles C. Fries and the Research Staff of the English Language Institute.

1. Intensive Course in English, Revised edition, 1953-1954.

Patterns of English Sentences, 1953, 150 pp.

English Pronunciation, 1954, $196 \mathrm{pp}$.

Lessons in Vocabulary, 1954, 54 pp.

Cumulative Pattern Practices, 1954, $171 \mathrm{pp.}$

(English Language Institute, Ann Arbor, Michigan.)

Charles C. Fries and Yao Shen

1. An Intensive Course in English for Chinese Students.

(English Language Institute, Ann Arbor, Michigan, 1946, 4 volumes, $1118 \mathrm{pp}$.)

Pauline Rojas and Staff of English Section, Dept. of Education, Puerto Rico with Charles C. Fries, Consultant and Advisor.

Fries American English Series, for the Study of English as a Second Language.

Books I and II, 1952, $226 \mathrm{pp}$. and $368 \mathrm{pp}$.

Books III and IV, 1953.

Book V, 1955.

Bpok VI (ready in 1956).

(These books cannot be used without the Teachers Guides.)

Teachers Guide for Books I and II, 1952, 261 pp. 


\section{THE TEACHING OF ENGLISH}

Teachers Guide for Books III and IV, 1953.

Teachers Guide for Book V, 1955.

Teachers Guide for Book VI (ready in 1956).

(These Teachers Guides contain also photographed pages of the books for the pupils.)

(D.C. Heath and Co., Boston, Massachusetts.)

\section{Edward Sapir}

1. Language (Harcourt, Brace \& Co., New York, 1921, 258 pp.).

2. "Sound Patterns in Language" (in Language, I, 1925).

\section{Leonard Bloomfield}

1. Language (Henry Holt \& Co., 1933, 509 pp.)

2. "Linguistics Aspects of Science" (in International Encyclopedia of Unified Science 1-4, University of Chicago Press, Chicago, 1939).

Kenneth L. Pike

1. The Intonation of American English. (University of Michigan Press, Ann Arbor, Michigan, 1945, 200 pp.).

2. Phonetics. (University of Michigan Press, 1942).

3. Phonemics. (University of Michigan Press, 1947, 254 pp.)

4. Tone Languages. (University of Michigan Press, 1948, $187 \mathrm{pp.).}$

5. Language in Relation to a Unified Theory of the Structure of Human Behaviour, Part I. (Summer Institute of Linguistics, Glendale, California, 1954, $170 \mathrm{pp}$.).

Harry Hoijer (ed.)

1. Linguistic Structures of North America. (Viking Fund, New York, 1946).

2. Language in Culture. (University of Chicago Press, 1954, 286 pp.).

S. I. Hayakama

1. Language in Thought and Action. (Harcourt, Brace and Co., New York, 1949).

Robert A. Hall

1. "American Linguistics, 1925-1950" (in Archivum Linguisticum, III, pp. 101-125, and IV, pp. 1-16).

Robert Lado

1. Annotated Bibliography for Teachers of English as a Foreign Language. (U.S. Government Printing Office, 1955, 224 pp.)

2. Linguistic Science and Language Tests (in Language Learning, III, 1950, pp. 15-82).

3. "Phonemics and Pronunciation Tests" (in Modern Language Journal, XXXV, 1951, pp. 531-542). 


\section{LANGUAGE LEARNING}

4. Test of Aural Comprehension (English Language Institute, Ann Arbor, 1946).

5. "Testing Control of the Structure of a Foreign Language" (in Language Learning, IV, 1951-2, pp. 17-35).

6. "The Relation of Entrance Level to Rate of Progress in Aural Comprehension" (in Language Learning, II, 1949), pp. 105-112).

Selected Articles from Language Learning, 1953, 211 pp. (Language Learning, 1522 Rackham Building, Ann Arbor, Michigan). 